2017 Theme Article:

Oral manifestations of

\title{
Candidiasis - has anything changed in the way we manage these patients?
}

E Blignaut

\section{SUMMARY}

Candida albicans remains an infection of the very old, the very young and the medically compromised patient. It not only affects the oral cavity but $C$. albicans biofilms form on most prosthetic devices and indwelling catheters with life-threatening consequences. The behaviour of this organism in biofilm formation has received much research interest. Understanding disease processes and the importance of prevention and disruption of $C$. albicans biofilms lie at the heart of successful treatment of such infections. Of equal importance is that patients also understand the rationale behind the treatment which will encourage adherence to the prescribed rigour. Experience in the South African context, together with the latest scientific evidence regarding the behaviour of C. albicans, is shared with the objective of enabling treatment leading to the effective and efficient resolution of the infection, but also to describe measures appropriate to prevent invasion by the organism.

\section{INTRODUCTION}

Oral candidiasis remains an infection that is associated with the very young, the elderly, the medically compromised and/or immunosuppressed individuals., ${ }^{1,2}$ Much has, however, changed in terms of our knowledge regarding the genetic composition, or genotype, and the behaviour, or phenotype, of the most frequently associated infectious agent, namely C. albicans. While C. dubliniensis received attention because of its initial association with HIV-patients in Europe,,$^{3,4}$ no consistent association has been established among South African HIV-patients. ${ }^{5}$ This article therefore will focus on $C$. albicans. Other Candida spp. associated with human colonisation include C. tropicalis, C. parapsilosis, C. glabrata, C. krusei, and C. lusitaneae, but these have mostly been isolated together with $C$. albicans, and have not yet been significantly implicated in oral disease in the South African context. ${ }^{6,7}$ C. albicans is carried in the mouths of approximately $50 \%$ of normal healthy individuals with a possible higher prevalence in intestinal sites. Under conditions of disease, the carriage rate as well as the number of colony forming units (cfu) isolated

Elaine Blignaut: BSc, MSc, HED, BChD, DHA (Dent), PhD, Dip Int Res Ethics. Department of Oral Pathology and Oral Biology, School of Dentistry, Faculty of Health Sciences, University of Pretoria, South Africa. P O Box 1266, Pretoria 0001, South Africa. Tel: 0123192523.

E-mail: Elaine.blignaut@up.ac.za

\section{ACRONYMS}

NUG/NUP: acute necrotising gingivitis/periodontitis

from a particular individual can increase significantly. When $C$. albicans is isolated from inanimate objects in the clinical setting, this is most likely due to contamination by humans or animals. ${ }^{8,9}$

\section{Characteristics of C. albicans}

C. albicans is referred to as a dimorphic or pleomorphic yeast due to the ability to switch between oval/round yeast cells and an elongated hyphal or fungal appearance. The foremost characteristic of C. albicans is its 'high degree of plasticity', which means that it is exceptionally well equipped to adapt to extremes in its macro- and micro-environment by switching between these different morphological forms. ${ }^{10}$ In a healthy mouth, the organism occurs as mainly vegetative, oval to round, budding yeast cells, referred to as blastoconidia, sometimes erroneously reported as Candida 'spores'. When the organism presents on smears as shorter or longer pseudohyphae or true hyphae, pathologists regard the appearance as an indication of disease and would report it as candidiasis. ${ }^{8,11}$

C. albicans propagates mainly through budding, or clonal expansion, as confirmed by DNA fingerprinting studies on large numbers of clinical isolates. ${ }^{12}$ These molecular studies have revealed approximately seven distinct genetic sub-groups, or clades, with some clades being found more frequently in particular geographic sites across the world. It may be relevant that none of these large studies could demonstrate any unique pathogenic subtypes of $C$. albicans that are frequently associated with disease. ${ }^{13-15}$ In addition, several studies have found the same genetic subtype of $C$. albicans to be associated with a particular individual throughout episodes of both health and disease, further dispelling the perception that there are specific pathogenic subtypes of the organism that cause disease and others that are commensals or normal flora. ${ }^{15,16}$ Another important finding regarding the predominant genetic subtype of $C$. albicans that was isolated from South African individuals, was a stable antifungal resistance to amphotericin B. This has developed as a result of the widespread use/abuse of a related antifungal agent, namely an aqueous oral solution of nystatin, as prophylaxis against or treatment 
of oral candidiasis.17,18 Findings like these support the global drive against the indiscriminate prescription of antimicrobial agents and that all attempts should be made to ensure a speedy and complete resolution of infections at the first attempt. ${ }^{19}$

Contrary to prior belief that C. albicans propagates exclusively through budding, DNA sequencing of the entire genome revealed mating type genes which later led to the discovery that the organism can indeed mate through a so-called 'parasexual' cycle. ${ }^{20}$ The term 'parasexual' is used because the DNA from the two mating cells in the zygote is not reduced through meiosis, or reduction division, as in other eukaryotic cells. This 'parasexual' behaviour of $C$. albicans was elucidated under a wide variety of laboratory conditions, many of which resembled conditions in the oral cavity, such as low oxygen supply, interaction with other micro-organisms and host defences. It is regarded as yet another mechanism by which the organism adapts to adverse conditions and protects itself against unfavourable environmental conditions or antifungal agents. ${ }^{21}$ The resultant offspring from this mating in biofilms were found to have varying amounts of DNA which is subsequently lost in a random fashion during repeated clonal propagation (budding). ${ }^{22,23}$ While unexplained at the time, earlier research investigating the genetic composition of $C$. albicans from periodontal pockets had found considerable variation in genetic composition. At the time the researchers were of the opinion that these isolates constituted unique pathogenic sub-species. ${ }^{24-26}$ However, the most recent research findings suggest that the most probable explanation is that in periodontal pockets the organism mated in an undisturbed biofilm, under anaerobic or low oxygen conditions, producing offspring with random amounts of DNA. ${ }^{23}$

Candida biofilms form on in-dwelling catheters, prosthetic joints and valves, and more importantly in the context of this article, on dentures, dental implants, orthodontic appliances and the oral mucosa. Because of the possible life threatening consequences, biofilm formation is receiving significant attention from both basic and clinical researchers with the number of publications having steadily increased from one in 1994 to approximately 300 per year in 2015.27 In a biofilm the increased fungal biomass of hyphae present an increased load of putative pathogenic traits, carried on the surface of the organism, as well as secreted, harmful enzymes. Extracellular matrix consisting of substances secreted by the organisms, and of food debris and desquamated epithelial cells, further contribute to the biofilm becoming impenetrable to antimicrobial agents. Not only are antifungal agents not capable of reaching the yeast cells, but C. albicans isolated from biofilms have been found to be resistant to antifungal agents. ${ }^{28}$ Investigation continues into a myriad of substances that may inhibit $C$. albicans biofilm formation on prosthetic surfaces but conclusive evidence has yet to emerge on agents that inhibit the process on the oral mucosa. ${ }^{29}$ The interaction between the organism and human mucosal surfaces, and how the oral mucosa itself may keep $C$. albicans in check receives equal attention. ${ }^{30}$ It is reiterated that $C$. albicans becomes pathogenic only when the host's defences permit and, most regrettably, often the first indication of an underlying failure in host defences is when oral candidiasis develops.

\section{TREATMENT}

The question is how all of this translates into the effective and efficient prevention and treatment of disease?

There are three important aspects to consider before prescribing antifungal agents to patients presenting with suspected Candida infections:

- Apart from pseudomembranous candidiasis which has a typical clinical presentation (Figures 1A, 1B and 2 ), it is strongly recommended that the presence of Candida hyphae is first confirmed before routinely prescribing an antifungal agent.

- While not in the scope of this article, all health professionals have a duty to either attempt to establish a possible underlying systemic condition in patients who present with oral candidiasis or to refer the patient to a medical doctor and to follow-up and ensure that the referral was indeed heeded and the patient is appropriately managed.

- Another very important aspect in the management of patients presenting with Candida infections is the disruption of biofilms and prevention of the formation thereof.

Candida does not become pathogenic unless the host's immune system is compromised. ${ }^{2}$ Specific antifungal agents and dosages are summarised in Table 1. Of importance is the application of that information, and the need for full understanding of the additional therapeutic measures, which should be conveyed to patients to ensure the complete resolution of the candida infections at the first attempt.

\section{Pseudomembranous candidiasis}

The topical antifungal treatment of choice remains Daktarin Oral Gel${ }^{\circledR}$. Not only has it been found to be effective in treating oral candidiasis but is available in both the public and private health sector. In order to ensure efficacy of the medication, patients should be instructed on how it should be applied. Approximately $1 \mathrm{~cm}$ of gel from the tube should be placed on the forefinger and applied everywhere on the oral mucosa and tongue, including the lateral borders of the tongue, with a rubbing action. The application is followed by swishing around in the mouth for a minute before swallowing. Rubbing results in the mechanical dislodging/disturbance of biofilm or the white pseudomembranous patches and may have a secondary effect in stimulating the circulation of the mucosa. Importantly, patients should be instructed to apply the gel after a meal and not to eat or drink for at least an hour. The final application at night should be immediately before going to bed and nothing should be consumed afterwards, keeping the medication in contact with the mucosa for as long as possible. It is recommended that patients continue this regimen three times daily for at least five days, during which time patients should be encouraged to exercise optimal oral hygiene to remove dental plaque which serves as a niche for $C$. albicans to thrive and co-exist with other micro-organisms. Patients should also be encouraged to eat solid food which could have some abrasive action in removing plaque or pseudomembranous patches. Upon resolution and if an underlying systemic cause was identified, patients should be encouraged to be vigilant regarding the formation of white patches and to gently brush the oral mucosa and tongue with a soft toothbrush, without causing injury. The existence of oral hairy leukoplakia is not contested, but in 
Table 1: Management of oral conditions involving $C$. albicans

\begin{tabular}{|c|c|c|}
\hline Condition & Agent and dosage & Application and special mention \\
\hline $\begin{array}{l}\text { Pseudomembranous, } \\
\text { erythematous candidiasis and } \\
\text { angular cheilitis associated } \\
\text { with oral candidiasis }\end{array}$ & $\begin{array}{l}\text { DaktarinOral Gel } \\
3 \text { times daily }\end{array}$ & $\begin{array}{l}\text { Spread on mucosa with rubbing } \\
\text { action. Do not eat or drink for at least } \\
1 \text { hour after application. Apply to the } \\
\text { corners of the mouth only and not } \\
\text { the lips. }\end{array}$ \\
\hline Oesophageal candidiasis & Diflucan $^{\circledast}$ or Sporanox ${ }^{\circledast}$ & $\begin{array}{l}\text { In consultation with or referral to a } \\
\text { medical doctor. }\end{array}$ \\
\hline $\begin{array}{l}\text { Angular cheilitis in the } \\
\text { absence of oral candidiasis }\end{array}$ & $\begin{array}{l}\text { Quadriderm cream. } \\
\text { Synalar C cream. }\end{array}$ & $\begin{array}{l}\text { Quadriderm or Synalar C should only } \\
\text { be applied to the corners of the mouth } \\
2-3 \text { times daily and not the lips or } \\
\text { the perioral skin. Decrease freeway } \\
\text { space of dentures. }\end{array}$ \\
\hline $\begin{array}{l}\text { Chronic hyperplastic } \\
\text { candidiasis }\end{array}$ & & $\begin{array}{l}\text { Refer to a medical practitioner or } \\
\text { hospital outpatient of emergency } \\
\text { department. }\end{array}$ \\
\hline Denture stomatitis & $\begin{array}{l}\text { Daktarin Oral Gel } \\
3 \text { times daily. }\end{array}$ & $\begin{array}{l}\text { Apply to oral mucosa, particularly } \\
\text { fitting surface of dentures. Apply to } \\
\text { dentures after thorough cleansing } \\
\text { and disinfecting in aqueous } 0,2 \% \\
\text { chlorhexidine solution. }\end{array}$ \\
\hline $\begin{array}{l}\text { Denture stomatitis in frail } \\
\text { elderly refractory to topical } \\
\text { antifungal treatment }\end{array}$ & $\begin{array}{l}\text { Diflucan }^{\circledR} \text { (Fluconazole) } \\
50-100 \mathrm{mg} \text { once daily for } \\
7-14 \text { days. } \\
\text { Sporanox } \\
100-200 \text { mg twice daily }\end{array}$ & $\begin{array}{l}\text { Cleanliness of dentures should be ex- } \\
\text { ercised. Trauma from ill-fitting dentures } \\
\text { should be eliminated. } \\
\text { Sporonox only in cases that may be } \\
\text { refractory to fluconazole. }\end{array}$ \\
\hline $\begin{array}{l}\text { Refractory chronic periodonti- } \\
\text { tis and peri-implant stomatitis }\end{array}$ & $\begin{array}{l}\text { Systemic Diflucan or } \\
\text { Sporanox }\end{array}$ & $\begin{array}{l}\text { Only upon confirmation of the } \\
\text { presence of Candida hyphae. }\end{array}$ \\
\hline
\end{tabular}

the experience of the author, white striations on the lateral border of the tongue have always been associated with pseudomembranous candidiasis, and disappear with resolution of the infection. Patients should therefore be reminded to also include the lateral borders of the tongue when applying medication.

The demonstration of C. albicans in carious dentine strongly suggests that the organism is continuously shed from carious teeth, with the potential to re-infect the oral mucosa. Wherever possible carious teeth with exposed dentine should be restored or removed if effective resolution of oral candidiasis is to be achieved, particularly if an underlying medical condition or immunosuppression prevails in patients. ${ }^{31}$

Despite the topical application of an aqueous oral solution of nystatin having been proven ineffective as both a prophylactic and therapeutic agent, it continues to be prescribed to adults. ${ }^{18}$ While nystatin itself has been shown to have some efficacy, it is probable that the aqueous solution/suspension does not provide for the antifungal to remain in contact with the mucosa for sufficient periods of time. Clinicians are urged to avoid prescribing this aqueous solution of nystatin to adult patients. In other countries a tablet formulation of nystatin has been found to be more effective, probably due to the carrier substance that permits a significantly longer contact period. . $^{32,33}$

\section{Denture stomatitis}

The irregular fitting surface of dentures is a well-known source of biofilm composed of Candida and other oral micro-organisms, and unless meticulous cleaning and disinfection of the dentures are performed, resolution of denture stomatitis will not be achieved. At the same time patients should ensure that the disinfectant be fully removed from dentures by thorough rinsing before replacement in the mouth as a chemical burn of thin and inflamed oral mucosa may occur. Daktarin Oral Gel ${ }^{\circledR}$ should also be applied to the fitting surfaces of dentures and the prostheses left out overnight for the duration of the treatment. Patients must be encouraged to brush the mucosa of the entire mouth with a soft

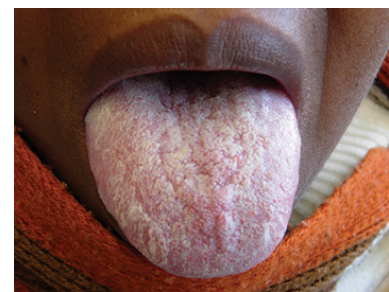

Figure 1A: Pseudomembranous candidiasis revealing the typical white pseudomembrane on tongue.

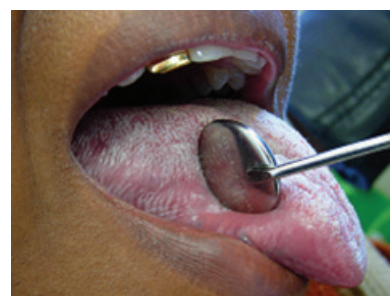

Figure 1B: Pseudomembranous candidiasis presenting as white striations on the lateral border of the tongue of the same patient.

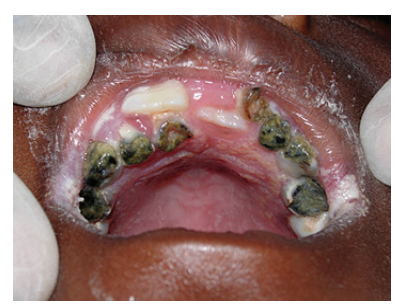

Figure 2: Rampant caries associated with pseudomembranous candidiasis in an HIV-positive child. Candidiasis recurred every 3-4 weeks until all carious teeth had been cleared.

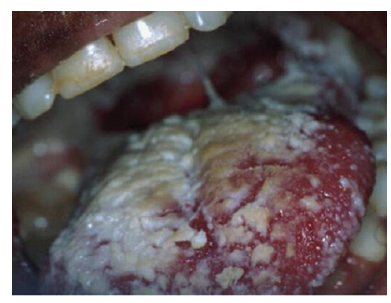

Figure 3: Hyperplastic candidiasis revealing thick, non-removable covering in a terminally ill patient. toothbrush, including the tongue and not only the areas covered by the dentures, before the gel is applied intra-orally. Brushing should be avoided, however, if the mucosa is thin and inflamed, in which case only gentle massaging with a finger is recommended when Daktarin Oral $\mathrm{Gel}^{\circledR}$ is applied. Care must be taken to ensure that the dentures do not cause mucosal trauma.

In elderly patients it may be warranted to prescribe systemic antifungal agents such as fluconazole or itraconazole if resolution is not achieved through the topical application of myconazole.

\section{Angular cheilitis}

It is seldom that this condition is due only to a Candida infection. It is encountered mostly in otherwise healthy edentulous patients or patients with ill-fitting dentures with excessive freeway space and saliva accumulating in the folds around the mouth. Frail elderly patients, malnourished edentulous patients, and/or very ill 
hospitalised patients are the other most likely candidates to present with angular cheilitis. If oral candidiasis or denture stomatitis are clinically diagnosed concomitantly with candidiasis, then the Daktarin Oral $\mathrm{Ge}^{\circledR}$ should also be applied to the corners of the mouth. As an alternative in the absence of oral candidiasis, topical agents such as Quadriderm ${ }^{\circledR}$ or Synalar $\mathrm{C}^{\circledR}$ can be prescribed, with special instructions not to apply these ointments widely to the skin of the perioral region or the rest of the lips. Attention should be paid to the improvement of the dentures in order to decrease freeway space whilst the attempt should be made to convince edentulous patients to have dentures.

Chronic periodontitis and or peri-implant mucositis The association of $C$. albicans in oral biofilms with other oral bacteria, including periodontal pathogens, further exacerbates the pathogenic qualities of Candida. ${ }^{34,35}$ Biofilm formation on dental implants has demonstrated the presence of $C$. albicans, but whether this plays a significant role is unclear. It is again emphasised that the presence of fungal hyphae should first be established through microscopy and/or culture before antifungal therapy is administered. When taking a specimen for a smear, all supra-gingival plaque should be removed before a sterile curette is passed along the length of the periodontal pocket or around an implant and the collected material smeared on a glass slide, fixed with an appropriate agent and sent to a laboratory for staining and microscopy. Sterile endodontic paper points may be inserted in the periodontal pocket after removal of supra-gingival plaque for the purpose of microbial culture. The reduction of periodontal pockets would facilitate maintenance of good oral hygiene and biofilm disruption. Only once the presence of Candida, refractory to conventional treatment, has been confirmed in periodontal lesions or peri-implant mucositis, can a systemic antifungal agent be prescribed. The management should include irrigation of periodontal lesions with an $0,2 \%$ aqueous solution of chlorhexidine. ${ }^{36,37}$

C. albicans does not play a contributory role in acute necrotising gingivitis/periodontitis (NUG/NUP). However, because this condition is also associated with immunosuppression, it should be established whether a patient presenting with NUG/NUP is also suffering from candidiasis. If so, the topical application of miconazole is recommended for the treatment of candidiasis together with chemotherapeutic agents and clinical debridement for NUG/NUP.

\section{Oesophageal candidiasis}

Once pseudomembranous candidiasis has spread to the oesophagus, it is obviously not possible to mechanically disrupt the pseudomembranes through rubbing. At this advanced stage of the disease (Figure 3), patients are generally very ill and the regular intake of food is hampered and it is best that they be referred to a medical practitioner for further management. If it would take time for such patients to reach a medical practitioner then systemic antifungal agents should be prescribed. In the public health sector special motivation is required when fluconazole (Diflucan ${ }^{\circledR}$ ) is prescribed. Fluconazole, as well as itraconazole $\left(\right.$ Sporazole $\left.^{\circledR}\right)$ are both available to patients in the private sector.

\section{Chronic hyperplastic candidiasis}

Patients presenting with this condition are rarely encountered in dental practice as they are very ill, most probably have other systemic conditions that require hospitalisation and should best be managed by a medical practitioner. In the unlikely event of a dental professional being consulted, it is best to direct the patient and or family to the nearest outpatient or emergency department of a hospital where the patient would hopefully be admitted and receive appropriate treatment.

\section{CONCLUSION}

While the reasons for the rising cost of health care in both public and private sectors across South Africa are debated, it is the patients who ultimately pay the price and health care professionals are urged to be prudent in the prescription of antimicrobial agents. Insight into disease processes or the nature of infecting agents will assist in the selection of the most appropriate treatment options together with the provision of appropriate advice to patients on maintaining health. Assumptions should not be made that Candida is indeed present but should be established through microscopy. In the case of oral conditions caused by $C$. albicans, there is no reason why resolution of the condition cannot be achieved with the initial treatment if patients are guided in the correct application of therapeutic agents (Table 1). Integral to the proper management of oral C. albicans infections is the recognition that an underlying systemic condition may be established, which may contribute to the fungus exerting pathogenic traits. Candidiasis seldom occurs in completely healthy individuals, a situation calling for closer collaboration between oral health professionals and their medical counterparts.

\section{References}

1. Stein P, Aalboe J. Dental care in the frail older adult: special considerations and recommendations. Journal of the California Dental Association 2015;43(7):363-8.

2. Pankhurst CL. Candidiasis (oropharyngeal). BMJ Clinical Evidence 2013:1304.

3. Coleman DC, Sullivan DJ, Mossman JM. Candida dubliniensis. Journal of Clinical Microbiology 1997;35(11):3011-2.

4. Coleman D, Sullivan D, Harrington B, Haynes K, Henman $M$, Shanley $D$, et al. Molecular and phenotypic analysis of Candida dubliniensis: a recently identified species linked with oral candidosis in HIV-infected and AIDS patients. Oral Diseases 1997;3 Suppl 1:S96-101.

5. Blignaut E, Pujol C, Joly S, Soll DR. Racial distribution of Candida dubliniensis colonization among South Africans. J Clin Microbiol 2003;41(5):1838-42.

6. Blignaut E. Oral candidiasis and oral yeast carriage among institutionalised South African paediatric HIV/AIDS patients. Mycopathologia. 2007 Feb;163(2):67-73.

7. Hauman $\mathrm{CH}$, Thompson IO, Theunissen F, Wolfaardt P. Oral carriage of Candida in healthy and HIV-seropositive persons. Oral Surgery, Oral Medicine, and Oral Pathology 1993;76(5):570-2.

8. Dignani MC, Solomkin JS, Anaissie EJ. Candida. In: Annaissie EJ, McGinnis MR, Pfaller MA, editors. Clinical Mycology. Philadelphia, USA: Churchill Livingston, 2003. p. 195-239.

9. Arendorf TM, Walker DM. Oral candidal populations in health and disease. Br Dent J 1979;147(10):267-72.

10. Soll DR. Candida commensalism and virulence: the evolution of phenotypic plasticity. Acta Trop 2002;81(2):101-10.

11. Zegarelli DJ. Fungal infections of the oral cavity. Otolaryngologic Clinics of North America 1993;26(6):1069-89.

12. Bougnoux ME, Pujol C, Diogo D, Bouchier C, Soll DR, d'Enfert 
C. Mating is rare within as well as between clades of the human pathogen Candida albicans. Fungal Genet Biol 2008;45(3):221-31.

13. Blignaut E, Pujol C, Lockhart S, Joly S, Soll DR. Ca3 fingerprinting of Candida albicans isolates from human immunodeficiency virus-positive and healthy individuals reveals a new clade in South Africa. J Clin Microbiol 2002;40(3):826-36.

14. L'Ollivier C, Labruere C, Jebrane A, Bougnoux ME, d'Enfert C, Bonnin A, et al. Using a Multi-Locus Microsatellite Typing method improved phylogenetic distribution of Candida albicans isolates but failed to demonstrate association of some genotype with the commensal or clinical origin of the isolates. Infect Genet Evol 2012;12(8):1949-57.

15. Odds FC. Molecular phylogenetics and epidemiology of Candida albicans. Future microbiology 2010;5(1):67-79.

16. Soll D. The ins and outs of DNA fingerprinting the infectious fungi. Clin Microbiol Rev 2000;13:332-70.

17. Blignaut E, Molepo J, Pujol C, Soll DR, Pfaller MA. Clade-related amphotericin B resistance among South African Candida albicans isolates. Diagn Microbiol Infect Dis 2005;53(1):29-31.

18. Blignaut E, Botes ME, Nieman HL. The treatment of oral candidiasis in a cohort of South African HIV/AIDS patients. Journal of the South African Dental Association 1999;54(12):605-8.

19. Nathan C, Cars O. Antibiotic resistance-problems, progress, and prospects. The New England Journal of Medicine 2014;371(19):1761-3.

20. Johnson A. The biology of mating in Candida albicans. Nature Reviews Microbiology 2003;1(2):106-16.

21. Berman J, Hadany L. Does stress induce (para)sex? Implications for Candida albicans evolution. Trends in Genetics : TIG 2012;28(5):197-203.

22. Hickman MA, Paulson C, Dudley A, Berman J. Parasexual ploidy reduction drives population heterogeneity through random and transient aneuploidy in Candida albicans. Genetics 2015;200(3):781-94.

23. Forche A. Large-scale chromosomal changes and associated fitness consequences in pathogenic fungi. Current Fungal Infection Reports 2014;8(2):163-70.

24. Lamster IB, Grbic JT, Mitchell-Lewis DA, Begg MD, Mitchell A. New concepts regarding the pathogenesis of periodontal disease in HIV infection. Ann Periodontol 1998;3(1):62-75.

25. Moore LV, Moore WE, Riley C, Brooks CN, Burmeister JA, Smibert RM. Periodontal microflora of HIV positive subjects with gingivitis or adult periodontitis. J Periodontol 1993:64(1):48-56.

26. Reynaud AH, Nygaard-Ostby B, Boygard GK, Eribe ER, Olsen I, Gjermo P. Yeasts in periodontal pockets. J Clin Periodontol 2001;28(9):860-4.

27. Soll DR, Daniels KJ. Plasticity of Candida albicans biofilms. Microbiology and Molecular Biology Reviews : MMBR 2016;80(3):565-95.

28. Borghi E, Borgo F, Morace G. Fungal biofilms: update on resistance. Advances in Experimental Medicine and Biology 2016;931:37-47.

29. Bandara HM, Matsubara VH, Samaranayake LP. Future therapies targeted towards eliminating Candida biofilms and associated infections. Expert Review of AntiInfective Therapy 2017;15(3):299-318.

30. Naglik JR, Richardson JP, Moyes DL. Candida albicans pathogenicity and epithelial immunity. PLoS Pathogens 2014;10(8):e1004257.

31. Blignaut E, van Heerden WF. Molecular and histological association between Candida albicans from oral soft tissue and carious dentine of HIV-positive children. Mycopathologia 2015;180(3-4):193-201.

32. Millns B, Martin MV. Nystatin pastilles and suspension in the treatment of oral candidosis. British Dental Journal 1996;181(6):209-11.

33. Schafer-Korting M, Blechschmidt J, Korting HC. Clinical use of oral nystatin in the prevention of systemic candidosis in patients at particular risk. Mycoses 1996;39(910):329-39.

34. Krom BP, Kidwai S, Ten Cate JM. Candida and other fungal species: forgotten players of healthy oral microbiota. J Dent Res 2014;93(5):445-51.

35. Canullo L, Penarrocha-Oltra D, Covani U, Rossetti PH. Microbiologic and clinical findings of implants in healthy condition and with peri-implantitis. The International Journal of Oral \& Maxillofacial Implants 2015;30(4):834-42.

36. Schwarz F, Becker K, Rahn S, Hegewald A, Pfeffer K, Henrich B. Real-time $\mathrm{PCR}$ analysis of fungal organisms and bacterial species at peri-implantitis sites. International Journal of Implant Dentistry 2015;1(1):9.

37. Drago L, Bortolin M, Taschieri S, De Vecchi E, Agrappi S, Del Fabbro M, et al. Erythritol/chlorhexidine combination reduces microbial biofilm and prevents its formation on titanium surfaces in vitro. Journal of Oral Pathology and Medicine. 2017;46(8):625-631.

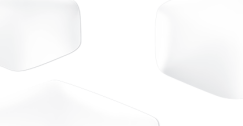

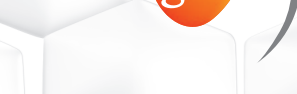 \\ SENSODYNE}

10

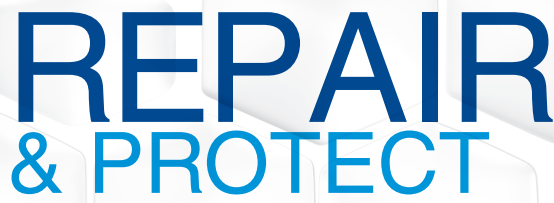

POWERED BY NOVAMIN

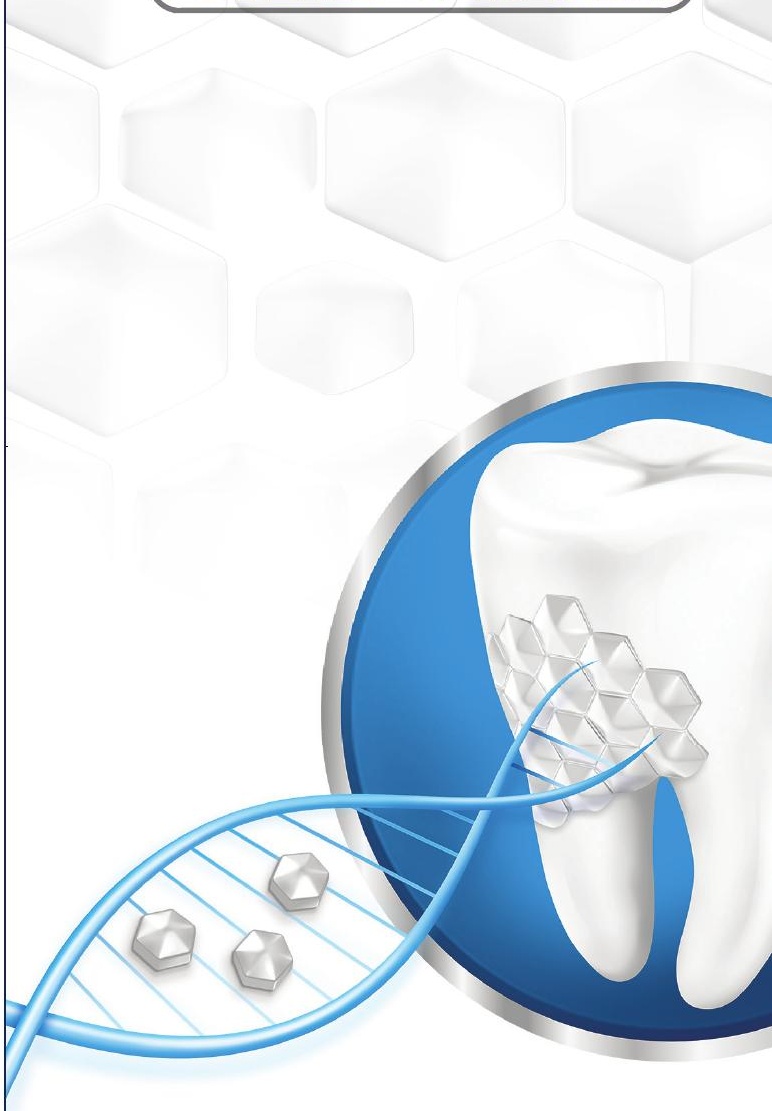

